\title{
Maternal obesity and major intraoperative complications during cesarean delivery
}

\author{
Marcela C. Smid, MD, MA, MS; Catherine J. Vladutiu, PhD, MPH; Sarah K. Dotters-Katz, MD; \\ Kim A. Boggess, MD; Tracy A. Manuck, MD, MSCl; David M. Stamilio, MD, MSCE
}

\begin{abstract}
BACKGROUND: Multiple studies have demonstrated an association between maternal obesity and postoperative complications, but there is a dearth of information about the impact of obesity on intraoperative complications.
\end{abstract}

OBJECTIVE: To estimate the association between maternal obesity at delivery and major intraoperative complications during cesarean delivery (CD). METHODS: This is a secondary analysis of the deidentified MaternalFetal Medicine Unit Cesarean Registry of women with singleton pregnancies. Maternal body mass index (BMI) at delivery was categorized as BMl 18.5 to $29.9 \mathrm{~kg} / \mathrm{m}^{2}$, BMl 30 to $39.9 \mathrm{~kg} / \mathrm{m}^{2}$, BMI 40 to $49.9 \mathrm{~kg} / \mathrm{m}^{2}$, and $\mathrm{BMI} \geq 50 \mathrm{~kg} / \mathrm{m}^{2}$. The primary outcome, any intraoperative complication, was defined as having at least 1 major intraoperative complication, including perioperative blood transfusion, intraoperative injury (bowel, bladder, ureteral injury; broad ligament hematoma), atony requiring surgical intervention, repeat laparotomy, and hysterectomy. Log-binomial models were used to estimate risk ratios of intraoperative complication in 2 models: model 1 adjusting for maternal race, and preterm delivery $<37$ weeks; and model 2 adjusting for confounders in Model 1 as well as emergency $C D$, and type of skin incision.

RESULTS: A total of 51,218 women underwent CD; $38 \%$ had BMI 18.5 to $29.9 \mathrm{~kg} / \mathrm{m}^{2}, 47 \%$ BMl 30 to $39.9 \mathrm{~kg} / \mathrm{m}^{2}, 12 \%$ BMI 40 to 49.9 $\mathrm{kg} / \mathrm{m}^{2}$ and $3 \% \mathrm{BMl} \geq 50 \mathrm{~kg} / \mathrm{m}^{2}$. Having at least 1 intraoperative complication was uncommon (3.4\%): $3.8 \%$ for BMl 18.5 to $29.9 \mathrm{~kg} /$ $\mathrm{m}^{2}, 3.2 \%$ BMl 30 to $39.9 \mathrm{~kg} / \mathrm{m}^{2}, 2.6 \%$ BMl 40 to $49.9 \mathrm{~kg} / \mathrm{m}^{2}$ and $4.3 \% \mathrm{BMl} \geq 50 \mathrm{~kg} / \mathrm{m}^{2}(P<.001)$. In the fully adjusted model 2 , women with BMl 40 to $49.9 \mathrm{~kg} / \mathrm{m}^{2}$ had a lower risk of any intraoperative complication (adjusted risk ratio [ARR], 0.76; 95\% confidence interval [Cl], 0.64 to 0.89) compared with women with BMl 18.5 to $29.9 \mathrm{~kg} / \mathrm{m}^{2}$. Women with BMl 30 to $39.9 \mathrm{~kg} / \mathrm{m}^{2}$ (ARR, 0.93; $95 \%$ $\mathrm{Cl}, 0.84$ to 1.03) had a similar risk of any intraoperative complication compared with nonobese women. Among super obese women, there was evidence of effect modification by emergency CD. Compared with nonobese women, neither super obese women undergoing nonemergency CD (ARR, 1.13; 95\% Cl, 0.84 to 1.52) nor those undergoing emergency CD (ARR, $0.59 ; 95 \% \mathrm{Cl}, 0.32$ to 1.10 ) had an increased risk of intraoperative complication.

CONCLUSION: In contrast to the risk for postcesarean complications, the risk of intraoperative complication does not appear to be increased in obese women, even among those with super obesity.

Key words: cesarean delivery, intraoperative complication, obesity, pregnancy, super obesity
I $\mathrm{n}$ the United States, nearly one third of reproductive-age women are obese. If current trends continue, more than one half of reproductive-age women will be obese by $20300^{1,2}$ Maternal obesity increases the risk of prolonged labor, failed induction, cesarean delivery $(\mathrm{CD})$ for failure to progress, and $\mathrm{CD}$ for emergency indications. $^{3-10}$ As maternal body mass index (BMI) increases, the risk of $\mathrm{CD}$ increases; nearly one half of women with class III obesity (BMI $\geq 40 \mathrm{~kg} / \mathrm{m}^{2}$ ) will delivery via CD. ${ }^{11,12}$ Maternal obesity also is associated with prolonged operative time ${ }^{13-15}$; however, it is unknown whether the management of intraoperative complications accounts for prolonged operative time during $\mathrm{CD}$.

Although the association between maternal obesity and postcesarean complications, including wound infection, ${ }^{14,16-18}$ venous thromboembolism, ${ }^{19}$ and postpartum hemorrhage, ${ }^{20,21}$ is well established, there is little information regarding the risk of intraoperative complications. The risk of intraoperative complications during gynecologic procedures appears to be similar or decreased among obese women compared with nonobese women. ${ }^{22-24}$ The objective of this study was to estimate the association between maternal obesity and the risk of intraoperative complications during CD. Our hypothesis was that similar to postcesarean complications, maternal obesity would be associated with an increased risk of intraoperative complications.

\section{Materials and Methods}

This is a retrospective cohort analysis of the Eunice Kennedy Shriver National Institute of Child Health and Human Development Maternal-Fetal Medicine Unit Cesarean registry, a prospective observational study conducted from 1999 to 2002 in 19 academic centers. This dataset is available publically and deidentified. Details about the study have been previously described. ${ }^{25}$ Study nurses collected information on each participant's demographics, obstetric history, and operative and delivery characteristics. For the present analysis, from the Cesarean Registry cohort $(\mathrm{n}=$ $73,257)$, we excluded women delivering via vaginal birth after $\mathrm{CD}(\mathrm{n}=13,850)$, multiple gestation $(n=4975)$, and those with missing information on BMI $(\mathrm{n}=$ $3053)$ or BMI $<18.5 \mathrm{~kg} / \mathrm{m}^{2}(\mathrm{n}=71)$.

Our primary exposure was maternal BMI at time of delivery stratified as BMI 18.5 to $29.9 \mathrm{~kg} / \mathrm{m}^{2}$, BMI 30 to 


\section{TABLE 1}

Maternal, clinical, and delivery characteristics, by maternal BMI, in the MFMU C-section registry from 1999 to 2002 $(n=51,218)$

\begin{tabular}{lcccc} 
& $\begin{array}{c}\text { BMl 18.5 to 29.9 } \\
(\mathbf{n}=19,527)\end{array}$ & $\begin{array}{c}\text { BMl 30 to 39.9 } \\
(\mathbf{n}=24,004)\end{array}$ & $\begin{array}{c}\text { BMI 40 to 49.9 } \\
(\mathbf{n}=6329)\end{array}$ & $\begin{array}{c}\text { BMI } \geq 50 \\
(\mathbf{n}=\mathbf{1 3 5 8})\end{array}$ \\
\hline Maternal age (years), median (IQR) & $28(23,33)$ & $29(24,33)$ & $28(24,33)$ & $28(24,32)$ \\
\hline Nulliparous & $5933(30.6)$ & $6424(26.9)$ & $1603(25.3)$ & $346(25.6)$ \\
\hline Black race & $4305(22.1)$ & $6725(28.0)$ & $2706(42.8)$ & $396(29.2)$ \\
\hline Previous CD & $11,036(56.5)$ & $14,991(62.5)$ & $4021(63.5)$ & $865(63.7)$ \\
\hline Preterm delivery (<37 weeks) & $4289(22.0)$ & $3471(14.5)$ & $986(15.8)$ & $229(16.9)$ \\
\hline Labor & $9607(49.2)$ & $11,176(46.6)$ & $2839(44.9)$ & $587(43.2)$ \\
\hline Emergency CD & $3778(19.4)$ & $3689(15.7)$ & $989(15.6)$ & $194(14.3)$ \\
\hline Skin incision & & & & \\
\hline Pfannenstiel & $11,316(58.0)$ & $12,550(52.3)$ & $3394(53.6)$ & $640(47.1)$ \\
\hline Vertical & $2310(11.8)$ & $3389(14.1)$ & $880(13.9)$ & $300(22.1)$ \\
\hline Unknown & $5901(30.2)$ & $8065(33.6)$ & $2055(32.5)$ & $418(30.8)$ \\
\hline Uterine incision & & & & \\
\hline Low transverse & $12,943(66.3)$ & $15,322(63.8)$ & $4048(64.0)$ & $814(59.9)$ \\
\hline Non-low transverse & $734(3.8)$ & $712(3.0)$ & $248(3.9)$ & $126(9.3)$ \\
\hline Unknown & $5,850(30.0)$ & $7,970(33.2)$ & $2,033(32.1)$ & $418(30.8)$ \\
\hline General anesthesia & $1651(8.5)$ & $1515(6.3)$ & $409(6.5)$ & $101(7.4)$ \\
\hline Operative time (min), median (IQR) & $45(35,57)$ & $49(38,61)$ & $55(43,69)$ & $63(51,83)$ \\
\hline Operative time (min) emergency CD, median (IQR) & $42(33,54)$ & $45(35,58)$ & $51(40,65)$ & $57(45,57)$ \\
\hline Operative time (min) nonemergency CD, median (IQR) & $45(36,58)$ & $50(39,62)$ & $55(44,70)$ & $65(52,85)$ \\
\hline
\end{tabular}

$\mathrm{n}(\%)$, unless indicated.

$C D$, cesarean delivery; IQR, interquartile range; MFMU, Maternal-Fetal Medicine Unit.

Smid et al. Maternal obesity and cesarean intraoperative complications. Am J Obstet Gynecol 2017.

$39.9 \mathrm{~kg} / \mathrm{m}^{2}$, BMI 40 to $49.9 \mathrm{~kg} / \mathrm{m}^{2}$, and BMI $\geq 50 \mathrm{~kg} / \mathrm{m}^{2}$. BMI was calculated from measured height and weight obtained at delivery or at the last prenatal visit within 2 weeks of delivery. There is no standard definition of obesity in pregnancy, particularly at time of delivery, our point of interest. We chose BMI at delivery, as opposed to prepregnancy BMI, because it accounts for gestational weight gain and reflects maternal habitus at time of delivery. We selected our BMI strata based on the literature and to reflect that one half of pregnant women will increase their World Health Organization prepregnancy BMI category by one or more categories. ${ }^{6}$

We also chose to include the emerging and clinically significant category of maternal super obesity
$\left(\mathrm{BMI} \geq 50 \mathrm{~kg} / \mathrm{m}^{2}\right),{ }^{11,14,16,18}$ because we hypothesized that super obese women would have the greatest risk of intraoperative complications. To internally validate our selection of BMI categories, we plotted the predicted probability of intraoperative complications by maternal BMI at delivery as a continuous variable. The primary outcome was defined as having at least one major intraoperative complication, including perioperative blood transfusion, intraoperative injury (bowel, bladder, ureteral injury; broad ligament hematoma), uterine atony requiring surgical intervention, repeat laparotomy, and hysterectomy.

We compared maternal demographics, clinical and delivery characteristics, and intraoperative complications across the 4 BMI categories using $\chi^{2}$ test for trend or Kruskal-Wallis, as appropriate. Log-binomial regression models were used to estimate risk ratios (RRs) and 95\% confidence intervals (CIs) for the association between obesity and intraoperative complications, adjusting for confounders. We initially identified candidate confounders by selecting historically relevant clinical factors and those that appeared to be associated with both exposure and outcome in unadjusted analyses, including maternal age, race, preterm delivery (PTD) $<37$ weeks, history of previous $C D$, labor, type of skin incision, anesthesia type, and emergency indication for CD. In the final multivariable models, we included only those confounders for which there was a difference of $\geq 10 \%$ between the 
Major intraoperative complications, by maternal BMI, among women delivered via cesarean delivery in the MFMU Cesarean registry, $1999-2002(n=51,218)$

\begin{tabular}{|c|c|c|c|c|c|c|}
\hline & $\begin{array}{l}\text { Total } \\
\mathrm{N}=51,218\end{array}$ & $\begin{array}{l}\text { BMI } 18.5 \text { to } 29.9 \\
(\mathrm{n}=19,527)\end{array}$ & $\begin{array}{l}\text { BMI } 30 \text { to } 39.9 \\
(\mathrm{n}=24,004)\end{array}$ & $\begin{array}{l}\text { BMI } 40 \text { to } 49.9 \\
(\mathrm{n}=7687)\end{array}$ & $\begin{array}{l}\text { BMI } \geq 50 \\
(\mathrm{n}=1358)\end{array}$ & $P$ value \\
\hline Any intraoperative complication ${ }^{a}$ & $1720(3.4)$ & 739 (3.8) & $757(3.2)^{b}$ & $165(2.6)^{b}$ & $59(4.3)$ & $<.001$ \\
\hline $\begin{array}{l}\text { Any intraoperative complication for } \\
\text { emergency cesarean delivery }\end{array}$ & $553(6.4)$ & $268(7.1)$ & $230(6.2)$ & $45(4.6)^{b}$ & $10(5.2)$ & .004 \\
\hline $\begin{array}{l}\text { Any intraoperative complication for } \\
\text { nonemergency cesarean delivery }{ }^{\mathrm{a}}\end{array}$ & $1167(2.7)$ & $471(3.0)$ & $527(2.6)$ & $120(2.3)$ & $49(4.1)$ & .21 \\
\hline Perioperative transfusion & $1208(2.6)$ & $537(2.8)$ & $523(2.2)^{b}$ & $105(1.7)^{\mathrm{b}}$ & $43(3.2)$ & $<.001$ \\
\hline Atony & $423(0.8)$ & $156(0.8)$ & $205(0.9)$ & $49(0.8)$ & $13(1.0)$ & .72 \\
\hline Operative injury $^{\mathrm{C}}$ & $259(0.5)$ & $127(0.7)$ & $102(0.4)^{b}$ & $25(0.4)^{b}$ & $5(0.4)$ & .001 \\
\hline Reoperation & $128(0.3)$ & $46(0.2)$ & $57(0.2)$ & $15(0.2)$ & $10(0.7)$ & .08 \\
\hline Hysterectomy & $278(0.5)$ & $110(0.6)$ & $131(0.6)$ & $33(0.5)$ & $4(0.3)$ & .33 \\
\hline
\end{tabular}

All values are $\mathrm{n}(\%)$. P value denotes $\chi^{2}$ test for trend.

$B M I$, body mass index; MFMU, Maternal-Fetal Medicine Unit.

${ }^{a}$ Includes perioperative transfusion, atony, operative injury, reoperation, hysterectomy; ${ }^{\mathrm{b}}$ Pair-wise comparisons with nonobese patients as the reference group are statistically significant $(P<.05)$ where denoted. All other pair-wise comparisons were not statistically significant; ${ }^{c}$ Bladder, bowel, or ureteral injury; broad ligament hematoma.

Smid et al. Maternal obesity and cesarean intraoperative complications. Am J Obstet Gynecol 2017.

unadjusted $\log -\mathrm{RR}$ and the confounderadjusted $\log -\mathrm{RR}$.

Because emergency $\mathrm{CD}$ has been associated with increased intraoperative complications compared with elective $\mathrm{CD},{ }^{26-28}$ we assessed the frequency of intraoperative complications between emergency and nonemergency $\mathrm{CD}$ stratified by BMI categories. We also explored interaction between BMI and emergency $\mathrm{CD}$ indication in our regression model, with $P<.1$ considered to be statistically significant. The definition of emergency and nonemergency $\mathrm{CD}$ was based on those indications for which decision to incision within 30 minutes is recommended. Emergency $\mathrm{CD}$ was defined as those performed for a primary indication of nonreassuring fetal status, cord prolapse, previa with bleeding, or placental abruption. Nonemergency CD was defined as those performed for a primary indication of elective $\mathrm{CD}$, labor dystocia, malpresentation, contraindication to labor, suspected macrosomia, previa without bleeding, and preeclampsia. ${ }^{29,30}$ Because $\mathrm{CD}$ after labor has been associated with both maternal obesity and increased intraoperative complications, ${ }^{7,26,31}$ we assessed both labor and second stage of labor as potential confounders and effect measure modifiers of the obesity effect on intraoperative complications. We also conducted a subgroup analysis of intraoperative complications for women undergoing elective repeat $\mathrm{CD}$.

There is significant controversy regarding the role of surgical characteristics such as emergency $C D$ and skin incision and whether they serve as confounders, mediators, or colliders of the association between maternal obesity and intraoperative complication. The optimal skin incision type for obese patients has not been determined by clinical research and consequently surgical technique for this population is quite variable. For example, a specific skin incision may be used based on provider or institutional preference, by necessity based on anatomic considerations, which could be affected by the severity or type of obesity (ie, adipose tissue distribution varies for individual women: "apple" vs "pear" shape"), or may be used based on the specific indication for surgical delivery (emergency vs nonemergency). ${ }^{32}$ Similarly, the role of emergency indication is difficult to determine because CD indication is associated with both intraoperative injury and obesity based on the literature and our findings. ${ }^{10}$

For surgical characteristics, including emergency $C D$ and skin incision, we present 2 adjusted models based on methodology described by Ananth and VanderWeele $^{33}$ : model 1 ("direct estimate") is adjusted for confounders assessed by the change-in-estimate approach (race and PTD $<37$ weeks) excluding surgical characteristics; and model 2 ("indirect estimate") further adjusts for skin incision types and emergency indication. We calculated the proportion of intraoperative complication mediated through surgical characteristics using the formula $(\mathrm{RRDE} \times[$ RRIE -1$] /[\mathrm{RRDE} \times$ RRIE - 1]), where RRDE and RRIE are the corresponding RRs for direct effect (of obesity) and indirect effect mediated through surgical characteristics. ${ }^{33}$ This approach allows us to present estimates that approximate the independent effect of obesity on intraoperative injury during $C D$ while still considering surgical characteristics as either confounders or mediators.

Analyses were conducted using Stata version 13 (College Station, TX). The University of North Carolina at Chapel 


\section{FIGURE 1}

\section{Predicted probability of intraoperative complication by maternal BMI at delivery $(n=51,218)$}

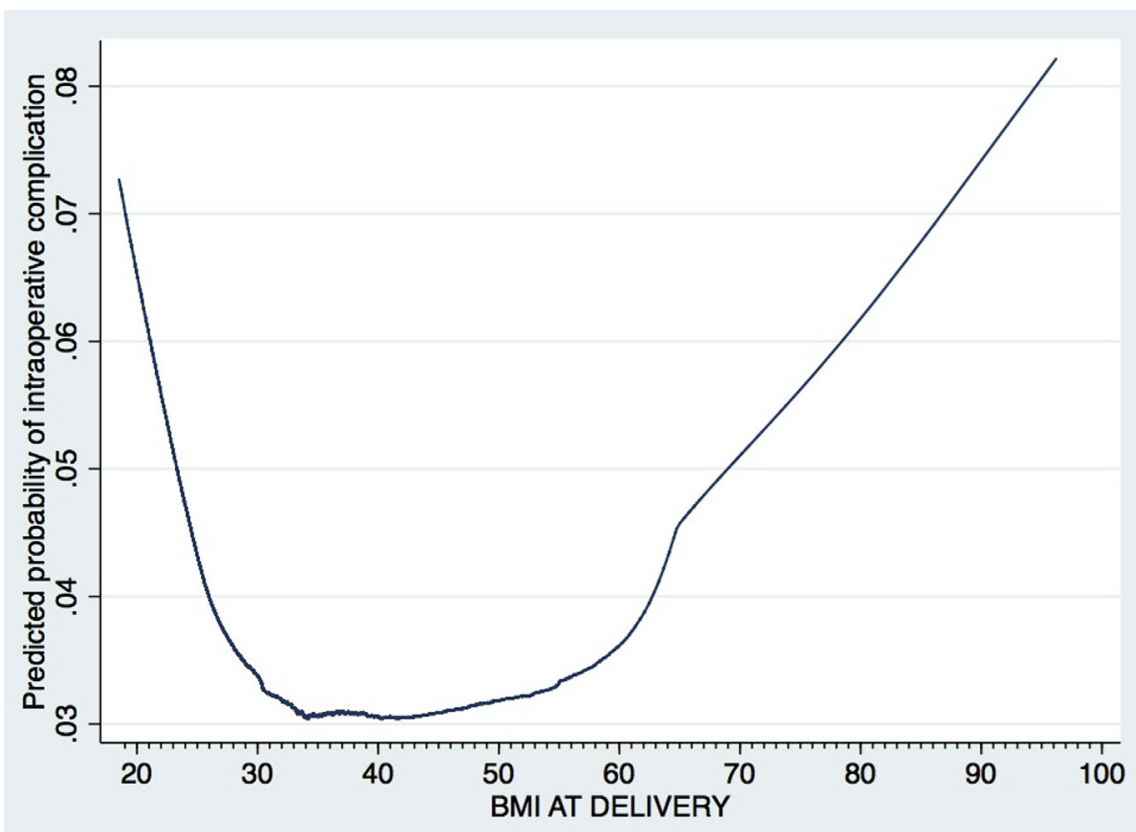

BMI, body mass index.

Smid et al. Maternal obesity and cesarean intraoperative complications. Am J Obstet Gynecol 2017.

Hill Institutional Review Board reviewed and deemed this study exempt.

\section{Results}

A total of 51,218 women met the eligibility criteria for this analysis. The distribution of maternal BMI categories was as follows: BMI 18.5 to $29.9 \mathrm{~kg} / \mathrm{m}^{2}$ (38\%), BMI 30 to $39.9 \mathrm{~kg} / \mathrm{m}^{2}$ (47\%), BMI 40 to $49.9 \mathrm{~kg} / \mathrm{m}^{2}(12 \%)$, and BMI $\geq$ $50 \mathrm{~kg} / \mathrm{m}^{2}$ (3\%). As maternal obesity increased, women were less likely to have labor before $\mathrm{CD}$ and to have an emergency CD (Table 1). Median operative time increased as obesity severity increased. Median operative time was also longer for nonemergency $\mathrm{CD}$ in each of the BMI categories compared with emergency CD.

Having at least 1 intraoperative complication was infrequent in this cohort $(\mathrm{n}=1720,3.4 \%)$, and twice as frequent among those who underwent emergency CD (6.4\%) compared with those who had a nonemergency CD (2.7\%) (Table 2). The observed point estimate of any intraoperative complication was the lowest among women with BMI 40 to $49.9 \mathrm{~kg} / \mathrm{m}^{2}$ and highest among those with BMI $\geq 50 \mathrm{~kg} / \mathrm{m}^{2}$. This pattern also was reflected when we plotted the predicted probability of intraoperative complication by maternal BMI at delivery as a continuous variable (Figure 1).

In our adjusted log-binomial models, we found that the risk of intraoperative complication in model 1 , adjusted for maternal race and PTD $<37$ weeks, and model 2 , same covariates as model 1 plus skin incision and emergency $\mathrm{CD}$, remained lowest among women with BMI 40 to $49.9 \mathrm{~kg} / \mathrm{m}^{2}$ (Table 3). There was no difference in the risk of at least 1 intraoperative complication among women with BMI 30 to $39.9 \mathrm{~kg} / \mathrm{m}^{2}$ or women with $\mathrm{BMI} \geq 50 \mathrm{~kg} / \mathrm{m}^{2}$ compared with women with BMI 18.5 to $29.9 \mathrm{~kg} /$ $\mathrm{m}^{2}$. The adjusted risk difference for intraoperative complications between women with BMI 18.5 to $29.9 \mathrm{~kg} / \mathrm{m}^{2}$ and BMI 40 to $49.9 \mathrm{~kg} / \mathrm{m}^{2}$ was $-0.0122(95 \%$ $\mathrm{CI},-0.017$ to 0.0074$)$. In other words, women with BMI 40 to $49.9 \mathrm{~kg} / \mathrm{m}^{2}$ had an estimated $1.2 \%$ absolute decrease in the probability of experiencing an intraoperative injury at time of $\mathrm{CD}$ compared with a woman with BMI 18.5 to $29.9 \mathrm{~kg} / \mathrm{m}^{2}$.

Labor and previous CD were not significant confounders and, thus, were not included in our final models. For CD after labor $(\mathrm{n}=21,067)$, there was no significant effect modification or confounding of the association between obesity and intraoperative complications by $\mathrm{CD}$ performed in the second stage. There was a statistically significant interaction found between BMI and emergency $C D$ indication only for super obese women $(P=.06)$. Among women undergoing nonemergency $C D$, super obese women were at increased risk of intraoperative complications compared with nonobese women, although the results were not statistically significant (super obese $\mathrm{n}=49$ [4.2\%] vs nonobese $\mathrm{n}=471$ [3.0\%], adjusted RR, 1.13; 95\% CI, 0.84 to 1.52). Among women undergoing emergency $\mathrm{CD}$, there was no difference in the odds of intraoperative complications between super obese and nonobese women, although the magnitude of effect was on the opposite side of the null (super obese $\mathrm{n}=10$ [5.2\%] vs nonobese 268 [7.1\%]; adjusted RR, 0.59; $95 \% \mathrm{CI}, 0.32$ to 1.10 ). Among women undergoing elective repeat $\mathrm{CD}(\mathrm{n}=$ 19,886) (13\% had CD after labor), there were no significant associations observed between BMI category and risk of intraoperative complications (data not shown).

\section{Conclusion}

In this large, multicenter cohort of women with singleton pregnancies undergoing primary and repeat $\mathrm{CD}$, we found that obesity is not associated with an increased risk of intraoperative complications. Contrary to our prestudy hypothesis, women with class III obesity (BMI 40 to 49.9) had a lower risk of intraoperative complications compared with nonobese patients. Our final regression models were, among other variables, adjusted for preterm delivery and (in model 2) type of skin incision, which have been associated previously with CD intraoperative complications. ${ }^{33,34}$ Although number of previous $\mathrm{CD}^{33,35}$ and labor before $\mathrm{CD}^{28}$ have been 
Log-binomial regression models for the risk of any intraoperative complication, by maternal BMI $(n=51,218)$

\begin{tabular}{|c|c|c|c|c|}
\hline & $\begin{array}{l}\text { Unadjusted RR } \\
(95 \% \mathrm{Cl})\end{array}$ & $\begin{array}{l}\text { Model 1: } \\
\text { direct } \\
\text { aRR }(95 \% \mathrm{Cl})\end{array}$ & $\begin{array}{l}\text { Model 2: indirect } \\
\text { aRR }(95 \% \mathrm{Cl})\end{array}$ & $\begin{array}{l}\text { Percent of intraoperative } \\
\text { risk attributable to } \\
\text { surgical characteristics }\end{array}$ \\
\hline BMI 18.5 to 29.9 (reference) & Reference & Reference & Reference & \\
\hline BMI 30 to 39.9 & $0.83(0.75-0.92)^{\mathrm{a}}$ & $0.87(0.82-1.00)$ & $0.93(0.84-1.03)$ & 32 \\
\hline BMI 40 to 49.9 & $0.69(0.58-0.81)^{\mathrm{a}}$ & $0.66(0.56-0.79)^{\mathrm{a}}$ & $0.76(0.64-0.89)^{\mathrm{a}}$ & 32 \\
\hline $\mathrm{BMI} \geq 50$ & $1.15(0.88-1.51)$ & $1.02(0.78-1.32)$ & $0.98(0.75-1.27)$ & 51 \\
\hline Non-Hispanic Black Race (ref nonblack) & $1.70(1.55-1.87)$ & $1.67(1.51-1.83)$ & $1.55(1.41-1.71)$ & \\
\hline PTD $<37$ weeks (ref $\geq 37$ weeks) & $2.44(2.22-2.69)^{\mathrm{a}}$ & $2.31(2.10-2.55)^{\mathrm{a}}$ & $2.01(1.82-2.23)^{\mathrm{a}}$ & \\
\hline \multicolumn{5}{|l|}{ Skin incision (ref vertical) } \\
\hline Pfannenstiel & $0.56(0.50-0.62)^{\mathrm{a}}$ & & $0.56(0.50-0.62)^{\mathrm{a}}$ & \\
\hline Unknown & $0.46(0.42-0.54)^{\mathrm{a}}$ & & $0.58(0.51-0.66)^{\mathrm{a}}$ & \\
\hline $\begin{array}{l}\text { Emergency cesarean delivery } \\
\text { (ref: nonemergency cesarean delivery) }\end{array}$ & $2.33(2.11-2.57)^{\mathrm{a}}$ & & $1.80(1.62-2.00)^{\mathrm{a}}$ & \\
\hline \multicolumn{5}{|l|}{ Model 1 adjusted for race and PTD < 37 weeks. } \\
\hline \multicolumn{5}{|c|}{ Model 2 adjusted for race, PTD < 37 weeks, skin incision type, and emergency cesarean delivery. } \\
\hline \multicolumn{5}{|c|}{$a R R$, adjusted risk ratio; $B M I$, body mass index; $C l$, confidence interval; $P T D$, preterm delivery; $R R$, risk ratio. } \\
\hline \multicolumn{5}{|c|}{ a Statistical significance at $P<.05$} \\
\hline
\end{tabular}

associated with increased risk of intraoperative injury, they were not significant risk factors in our model.

Among women undergoing $\mathrm{CD}$ after labor, second stage also was not a significant risk factor. Our findings are consistent with studies demonstrating that operative times were longer for more severely obese women ${ }^{15}$ and that the frequency of intraoperative complication varies by emergency and nonemergency $\mathrm{CD}^{26,27}$ In our adjusted model, emergency CD was associated with an increased risk of intraoperative complications, which is consistent with other studies. ${ }^{26,34,36}$ Our findings also suggest that surgical characteristics (skin incision and emergency $\mathrm{CD}$ ) are not the primary mediators through which maternal obesity is associated with a decreased or similar risk of intraoperative injury at time of CD compared with nonobese women. Among women with $\mathrm{BMI}<50$, approximately one third $(32 \%)$ of intraoperative injury is mediated through measured surgical characteristics, and this proportion is approximately one half (51\%) for women with $\mathrm{BMI} \geq 50 \mathrm{~kg} / \mathrm{m}^{2}$. Using the approach of assessing direct and indirect effects, we are able to estimate that the effects of maternal obesity on risk of intraoperative complications are not solely mediated by the measured surgical characteristics.

There are limited studies examining obesity as a risk factor for intraoperative complications during $\mathrm{CD}$, and results are conflicting. In a single-center study, lower maternal BMI was associated with an increased risk of bladder injury at time of $\mathrm{CD}^{33}$ In a large Finnish cohort, obese women $(\mathrm{BMI} \geq 30)$ had a greater risk of reoperations compared with women with BMI $20-30 \mathrm{~kg} / \mathrm{m}^{2}$, but no difference was observed for intraoperative injuries (organ injuries and lacerations) or hemorrhage (defined as estimated blood loss [EBL] $>1500 \mathrm{~mL}$ and/or blood transfusion). ${ }^{34}$

In an analysis of the same cohort used for our analysis, Hibbard et $\mathrm{al}^{37}$ reported that among women with BMI $\geq 40$ undergoing a trial of labor compared with elective repeat $\mathrm{CD}$, there were no differences in transfusion, operative injury, or hysterectomy. Our study indicates that there may be no difference in intraoperative injury risk or perhaps even a decreased risk among some obese women (BMI 40 to $49.9 \mathrm{~kg} / \mathrm{m}^{2}$ ) compared with nonobese women. Although we assessed whether surgical characteristics, including operative urgency and surgical technique, may have mediated the risk for surgical complications, there may be unmeasured confounding of the association between maternal obesity and intraoperative complications by other surgical characteristics not measured in this dataset. We hypothesize that these findings may be explained by the possibility that severity of maternal obesity may have heightened surgeons' preparedness for the surgery or altered the approach (ie, use of surgical retraction devices or surgical assistants for improved exposure), thus increasing total operative time but decreasing complications.

Our study has several strengths. The large size and multicenter nature of the study allows us to investigate rare outcomes such as major intraoperative complications. Our overall intraoperative complication frequency was $3.4 \%$, comparable with that reported by others, which range from 4.4 to $15 \%{ }^{28,34,38}$ Although other studies have frequencies that are slightly greater than 
our study, these other studies all include EBL $>1000-1500 \mathrm{~mL}$ as part of their intraoperative complications. ${ }^{28,36} \mathrm{We}$ chose to include blood transfusion because EBL is not available in this dataset and varies by center and transfusion is a more objective and clinically significant marker of severe hemorrhage. Obese women are known to have longer operative time, and our results indicate that these longer operative times are likely not attributable to increased need for intraoperative complication management. ${ }^{16,18}$ We focused on intraoperative complications with the most severe sequelae, particularly those requiring further intraoperative management.

The study has limitations. Our study includes a large number of women, and our finding of decreased risk of intraoperative complications in the BMI 40 to $49.9 \mathrm{~kg} / \mathrm{m}^{2}$ group compared with the nonobese group may reflect a Type I error; however, we consistently found that maternal obesity does not increase the risk of intraoperative complications. Thus, we feel confident in reporting that in contrast to the increased risk of postcesarean complications, obese women do not appear to be at increased risk of intraoperative complications.

We did assess both labor and secondstage $\mathrm{CD}$ among those women undergoing $\mathrm{CD}$ after labor, which were not statistically significant risk factors. It is also possible that fetal head station may play a role in intraoperative complications. Because more than $20 \%$ of women were missing data for this variable, however, we were not able to reliably assess the role of fetal head station using this data set. Our finding that labor was not a significant risk factor for intraoperative complications is contrary to other studies. ${ }^{26,27,34,39}$ Our study includes more than 50, 000 women, however, and is much larger than any of these single-center studies. It is possible that the specific labor management practices in these single centers impacts the risk of intraoperative complications; however, in our study of 19 tertiary care centers, labor management practices vary and were not a significant risk factor for intraoperative injury.
Although BMI is an appropriate and readily available assessment of obesity for large studies, other measures of adiposity distribution in the nonobstetric population, such as increased waist-to-hip ratio, have been associated with intraoperative and other complications and may be more predictive of these complications than BMI. ${ }^{40,41}$ In pregnancy, uterine distension may distort waist-to-hip ratio. Prospective studies are needed to assess whether increased central obesity impacts intraoperative complication, particularly among super obese women. Although we assessed for confounding variables, we did not have information on other variables such as degree of adhesive disease and previous intra-abdominal surgeries, which may impact risk of intraoperative disease. Residual confounding by these and other unmeasured covariates may have biased the associations that were observed. We were also unable to assess the surgeons' experience level, including resident involvement. It is plausible that more experienced surgeons may have been more likely to perform $\mathrm{CD}$ in the more obese groups; however, other studies have shown no difference in intraoperative complication by surgeon level of training. ${ }^{27,31}$ This potentially unmeasured confounding may explain or partially account for the observed relationship between maternal obesity and intraoperative risk in this cohort. This study was performed at tertiary care academic centers, which may have access to more specialized equipment to accommodate women with severe obesity and extra staff; thus, information in this analysis may not be applicable to all delivering institutions particularly those centers in populations with a lower prevalence of obesity.

Our study has demonstrated that in tertiary care centers, obese women, including the most severely obese women, have longer operative times but do not appear to be at increased risk of intraoperative complications compared with nonobese women. The decreased risk of intraoperative complication among women with BMI 40 to $49.9 \mathrm{~kg} /$ $\mathrm{m}^{2}$ is not likely to be explained by a protective effect of increased adipose tissue but rather by some unmeasured surgical technique. Thus, we caution against any causal interpretations between maternal obesity and decreased intraoperative risk and suggest that this information presented here be used in counseling obese women about risk of $\mathrm{CD}$ and for hypothesis generation in future studies. Obstetricians increasingly are faced with delivering obese women via $C D$, and these studies are urgently needed to characterize if and how the distribution of adiposity may impact perioperative risk.

\section{References}

1. Wang $Y$, Beydoun MA, Liang L, Caballero B, Kumanyika SK. Will all Americans become overweight or obese? Estimating the progression and cost of the US obesity epidemic. Obesity 2008;16:2323-30.

2. Flegal KM, Carroll MD, Kit BK, Ogden CL. Prevalence of obesity and trends in the distribution of body mass index among US adults, 1999-2010. JAMA 2012;307:491-7.

3. Stotland NE, Hopkins LM, Caughey AB. Gestational weight gain, macrosomia, and risk of cesarean birth in nondiabetic nulliparas. Obstet Gynecol 2004;104:671-7.

4. Crane JM, Murphy P, Burrage L, Hutchens D. Maternal and perinatal outcomes of extreme obesity in pregnancy. J Obstet Gynaecol Can 2013;35:606-11.

5. Chu SY, Kim SY, Schmid CH, et al. Maternal obesity and risk of cesarean delivery: a metaanalysis. Obes Rev 2007;8:385-94.

6. Kabiru W, Raynor BD. Obstetric outcomes associated with increase in BMl category during pregnancy. Am J Obstet Gynecol 2004;191: 928-32.

7. Carlhall S, Kallen K, Blomberg M. Maternal body mass index and duration of labor. Eur J Obstet Gynecol Reprod Biol 2013;171:49-53.

8. Kominiarek MA, Vanveldhuisen P, Hibbard J, et al. The maternal body mass index: a strong association with delivery route. Am J Obstet Gynecol 2010;203:264.e1-7.

9. Kominiarek MA, Zhang J, Vanveldhuisen $P$, Troendle J, Beaver J, Hibbard JU. Contemporary labor patterns: the impact of maternal body mass index. Am J Obstet Gynecol 2011;205: 244.e1-8.

10. Poobalan AS, Aucott LS, Gurung $T$, Smith WC, Bhattacharya S. Obesity as an independent risk factor for elective and emergency caesarean delivery in nulliparous women-systematic review and meta-analysis of cohort studies. Obes Rev 2009;10:28-35.

11. Marshall NE, Guild C, Cheng YW, Caughey AB, Halloran DR. Maternal superobesity and perinatal outcomes. Am J Obstet Gynecol 2012;206:417.e1-6. 
12. Marshall NE, Guild C, Cheng YW, Caughey AB, Halloran DR. Maternal superobesity and perinatal outcomes. Acta Obstet Gynecol Scand 2010;89:924.

13. Perlow JH, Morgan MA. Massive maternal obesity and perioperative cesarean morbidity. Am J Obstet Gynecol 1994;170:560-5.

14. Conner SN, Verticchio JC, Tuuli MG, Odibo AO, Macones GA, Cahill AG. Maternal obesity and risk of postcesarean wound complications. Am J Perinatol 2014;31:299-304.

15. Girsen Al, Osmundson SS, Naqvi M, Garabedian MJ, Lyell DJ. Body mass index and operative times at cesarean delivery. Obstet Gynecol 2014;124:684-9.

16. Smid MC, Kearney MS, Stamilio DM. Extreme obesity and postcesarean wound complications in the maternal-fetal medicine unit cesarean registry. Am J Perinatol 2015;32: 1336-41.

17. Alanis MC, Villers MS, Law TL, Steadman EM, Robinson CJ. Complications of cesarean delivery in the massively obese parturient. Am J Obstet Gynecol 2010;203: 271.e1-7.

18. Stamilio DM, Scifres CM. Extreme obesity and postcesarean maternal complications. Obstet Gynecol 2014;124:227-32.

19. Robinson HE, O'Connell CM, Joseph KS, McLeod NL. Maternal outcomes in pregnancies complicated by obesity. Obstet Gynecol 2005; 106:1357-64.

20. Sebire NJ, Jolly M, Harris JP, et al. Maternal obesity and pregnancy outcome: a study of 287 , 213 pregnancies in London. Int J Obes Relat Metab Disord 2001;25:1175-82.

21. Blomberg M. Maternal obesity and risk of postpartum hemorrhage. Obstet Gynecol 2011;118:561-8.

22. Chen CCG, Collins SA, Rodgers AK, Paraiso MFR, Walters MD, Barber MD. Perioperative complications in obese women vs normal-weight women who undergo vaginal surgery. Am J Obstet Gynecol 2007;197:98. e1-8.

23. Rogers R, Lebküchner U, KammererDoak D, Thompson P, Walters M, Nygaard I. Obesity and retropubic surgery for stress incontinence: is there really an increased risk of intraoperative complications? Am J Obstet Gynecol 2006;195:1794-8.
24. Nam K-H, Jeon M-J, Hur H-W, Kim S-K, Bai S-W. Perioperative and long-term complications among obese women undergoing vaginal surgery. International Journal of Gynecol Obstet 2010;108:244-6.

25. Landon MB. Predicting uterine rupture in women undergoing trial of labor after prior cesarean delivery. Semin Perinatol 2010;34:267-71. 26. Nielsen TF, Hokegard KH. Cesarean section and intraoperative surgical complications. Acta Obstet Gynecol Scand 1984;63:103-8.

27. Bergholt T, Stenderup JK, VedstedJakobsen A, Helm P, Lenstrup C. Intraoperative surgical complication during cesarean section: an observational study of the incidence and risk factors. Acta Obstet Gynecol Scand 2003;82: 251-6.

28. Van Ham MA, Van Dongen PW, Mulder J. Maternal consequences of caesarean section. A retrospective study of intra-operative and postoperative maternal complications of caesarean section during a 10-year period. Eur J Obst Gynecol Reprod Biol 1997;74:1-6.

29. Bloom SL, Leveno KJ, Spong CY, et al. Decision-to-incision times and maternal and infant outcomes. Obstet Gynecol 2006;108:6-11.

30. American Academy of Pediatrics American College of Obstetricians and Gynecologists. Guidelines for perinatal care. 7th ed. Washington, DC: Elk Grove Village IL: American Academy of Pediatrics American College of Obstetricians and Gynecologists; 2012.

31. Phipps MG, Watabe B, Clemons JL, Weitzen S, Myers DL. Risk factors for bladder injury during cesarean delivery. Obstet Gynecol 2005;105:156-60.

32. Smid MC, Smiley SG, Schulkin J, Stamilio DM, Edwards RK, Stuebe AM. The problem of the pannus: physician preference survey and a review of the literature on cesarean skin incision in morbidly obese women. Am J Perinatol 2016;33:463-72.

33. Ananth CV, VanderWeele TJ. Placental abruption and perinatal mortality with preterm delivery as a mediator: disentangling direct and indirect effects. Am J Epidemiol 2011;174: 99-108.

34. Pallasmaa N, Ekblad U, Aitokallio-Tallberg A, et al. Cesarean delivery in Finland: maternal complications and obstetric risk factors. Acta Obstet Gynecol Scand 2010;89:896-902.
35. Silver RM, Landon MB, Rouse DJ, et al. Maternal morbidity associated with multiple repeat cesarean deliveries. Obstet Gynecol 2006;107:1226-32.

36. Bergholt T, Stenderup JK, VedstedJakobsen A, Helm P, Lenstrup C. Intraoperative surgical complication during cesarean section: an observational study of the incidence and risk factors. Acta Obstet Gynecol Scand 2003;82: 251-6.

37. Hibbard JU, Gillbert S, Landon MB, et al. Trial of labor or repeat cesarean delivery in women with morbid obesity and previous cesarean delivery. Obstet Gynecol 2006;108:125-33.

38. Bergholt T, Lim LK, Jørgensen JS, Robson MS. Maternal body mass index in the first trimester and risk of cesarean delivery in nulliparous women in spontaneous labor. Am J Obstet Gynecol 2007;196:163.e1-5.

39. Bakketeig LS, Jacobsen G, Skjærven R, Carneiro IG, Knudsen LB. Low birthweight and mortality: the tendency to repeat low birthweight and its association with early neonatal and infant morbidity and mortality. Paediatr Perinat Epidemiol 2006;20:507-11.

40. Kartheuser AH, Leonard DF, Penninckx F, et al. Waist circumference and waist/hip ratio are better predictive risk factors for mortality and morbidity after colorectal surgery than body mass index and body surface area. Ann Surg 2013;258:722-30.

41. Joseph B, Zangbar B, Haider AA, et al. Hips don't lie: waist-to-hip ratio in trauma patients. J Trauma Acute Care Surg 2015;79:1055-61.

\section{Author and article information}

Division of Maternal Fetal Medicine, Department of Obstetrics and Gynecology, University of North Carolina-Chapel Hill, Chapel Hill, NC.

Received May 12, 2016; revised Sept. 23, 2016; accepted Feb. 7, 2017.

Dr Smid is now affiliated with the Division of Maternal Fetal Medicine, Department of Obstetrics and Gynecology, University of Utah. Salt Lake City, UT.

The authors report no conflict of interest.

This paper was presented as poster at the 36th annual meeting of the Society of Maternal Fetal Medicine, Atlanta, GA, Feb. 1-6, 2016 (final abstract ID \#375).

Corresponding author: Marcela Smid, MD. Marcela. Smid@hsc.utah.edu 